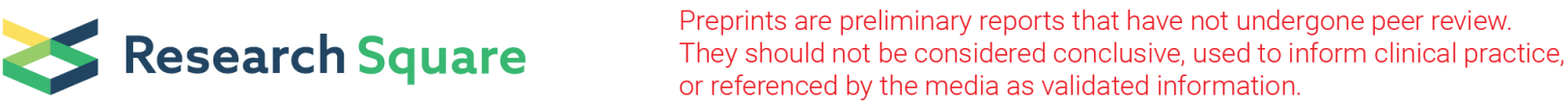

\section{An Exploratory Study on The Association Between Gender and Factors That Influence Animal-Source Food Dietary Intake for Households In Lower- Income Urban Informal Settings of Nairobi, Kenya}

\section{Mariah Ngutu}

University of Nairobi, Institute of Anthropology, Gender and African Studies

Salome A. Bukachi ( $\sim$ salome.bukachi@uonbi.ac.ke )

University of Nairobi https://orcid.org/0000-0002-1931-1891

Ann W. Muthiru

University of Nairobi, Institute of Anthropology, Gender and African Studies

Aurélia Lépine

University College of London

Suneetha Kadiyala

London School of Hygiene \& Tropical Medicine

Paula Domínguez-Salas

University of Greenwich Natural Resources Institute

\section{Research}

Keywords: Gender, Socio-cultural factors, Decision making, Dietary intake, Animal-source foods (ASFs)

Posted Date: January 8th, 2021

DOl: https://doi.org/10.21203/rs.3.rs-140034/v1

License: (c) (i) This work is licensed under a Creative Commons Attribution 4.0 International License.

Read Full License 


\section{Abstract}

Background: Low-quality monotonous diets dominated by starchy foods are a major problem confronting resource-constrained settings worldwide including poor households in the urban informal settings of Nairobi, Kenya. This low-quality dietary intake is fueled by socio-economic disparities further complicated by gender hegemonies that influence decision making in food choice and consumption. This places the population, especially women of reproductive age and young children, at a risk of micronutrients deficiencies, such as anemia. Animal-source foods (ASFs) are high-quality nutrient-dense products that supply essential amino-acids, vitamins and minerals, to reduce stunting and micronutrient deficiencies. Previous research showed that the poorest households in Nairobi, Kenya, had low Animal-source foods (ASFs) consumption.

Food security and nutrition dimensions of food security such as the gendered dimensions have been the main focus in most development interventions. However, there still exists gaps especially at the household level that try to understand the association between gender and factors that influence animalsource food dietary intake.

Methods: An exploratory qualitative study was carried out to establish the association between gender and factors that influence animal-source foods dietary intake for households in lower-income urban informal settings of Nairobi, Kenya. We utilized 19 focus group discussions with embedded participatory exercises and 60 in-depth interviews differently for men and women alongside unstructured observations to enable in-depth exploration of ASFs consumption and choice determinants.

Results: Gender and related factors including decision making, power position dynamics of men and women as well as coping mechanisms were seen to influence household ASF dietary intake. Both men and women had a role providing for food budgets and also deciding on when and what ASF would be consumed in their households. Notably, men and women in the informal low-income settings face socioeconomic challenges in planning for and sustaining household food needs including ASF.

Conclusion: Nutrition and health interventions and programs tackling malnutrition in lower-income households need to consider the gender and associated factors as identified in this exploratory research. These factors are seen as intersecting with the household economic status and sociocultural practices to influence ASF dietary intake including choice and consumption.

\section{Background}

Food insecurity is still prevalent in many parts of the world with gender disparities identified as one of the key drivers especially in developing countries [1]. A key component of food insecurity is lack of access to a sufficient quantity of nutritious food, which is a potential risk factor for malnutrition in children and adults [1]. However, there is limited evidence on the association between household and individual nutrition insecurity and malnutrition [1]. Food security is a complex and multidimensional phenomenon defined as a state when "all people, at all times, have physical, social and economic access to sufficient, 
safe and nutritious food that meets their dietary needs and food preferences for an active and healthy life" [2]. Within households it depends on who has control over cash income; that is the major decisionmaker, and market prices. Gender expectations are shaped and intertwine with, and within the broader socioecological system that defines men and women in society.

Despite ongoing efforts to alleviate food insecurity in Kenya, estimates indicate that approximately $50 \%$ of Kenyans are food insecure with $10 \%$ in constant need of food relief [3]. With a surge in urban informal settlements there is overcrowding and resultant challenging environments that lack accessible roads, health, housing water and sanitation services. Availability of and access to safe nutritious food is a major challenge for populations in these lower-income settings [4]. The nutrition and health status of these communities is hinged on multiple intersecting factors including access to cash incomes, food, quality, health services or water and sanitation which depend on political and policy frameworks. Using dietary diversity among households in lower-income urban informal settings, Dominguez-Salas et al., found that socio-economic and gender factors are critical when addressing the question of food security from the demand side [5]. Other factors hypothesized in the literature to negatively influence food security include: family size and dependency ratio $[3,4,5,6]$. This places the population, especially women of reproductive age and young children, at a risk of micronutrients deficiencies such as anemia and stunting $[1,3,4]$.

Animal-source foods (ASFs) are high-quality nutrient-dense products that supply essential amino-acids, vitamins and minerals, to prevent micronutrient deficiencies including stunting and anemia and promote cognitive development [7]. Previous research showed that the lower income households in Nairobi's urban informal settlements had low ASFs consumption [4]. Food consumption is highly regulated by social, cultural, environmental and economic factors, and ASFs tend to be among the most regulated across all settings $[1,6,8]$. In most settings where differential consumption patterns do occur, the differences tend to be on luxury foods (non-staple foods), such as ASF, rather than necessity foods (staple foods) [9].

There is evidence to support the impact of ASFs on the nutrition and health status of marginal populations including those in informal settings around the world [1, 3, 4, 5]. Harris-Fry et al. point out that ASFs even in relatively small quantities can make a significant difference in the nutrition and health of children and adults; increased ASFs intake is linked to many different types of health outcomes; and that ASFs are an important component of dietary quality and diversity, even when economic factors are controlled [6]. Various studies on ASFs consumption have shown that access to these food groups within the household or community depends on age, gender and power relations, which in turn, affect ability of individual's nutrition situation $[1,2,5,10]$. Food security has been a dominant focus in development interventions and research, the gendered dimensions is receiving increasing attention $[4,11,12]$. Ultimately, the dynamics between gender and associated factors including power, social systems, and complex food landscapes influences decision-making on the dietary intake to dictate how much of what kind of food including ASFs is consumed when and by whom in the households. Food, including ASF, choice and consumption patterns in households indicate specialized knowledge of specific members and the responsibilities and roles attached to certain subjectivities. This paper presents findings of an exploratory study that examined gender and associated factors influencing ASF dietary intake for 
households in Nairobi's informal settlements to provide qualitative based analysis across gender categories within ASF access and nutrition experiences.

\section{Methods}

The exploratory study design triangulated qualitative methods to examine gender and associated factors influencing ASF dietary intake in low-income households of Dagoretti North and South, in Nairobi county, Kenya, between October and December 2019. Dagoretti sub-counties (North and South) are peri-urban, with low-income residential settlements and has lower population density than other areas of Nairobi. Notably though, these areas have a higher density of livestock, leading to the multiplicity of ASF value chains and hence diversity, a key consideration for the study setting selection.

The study participants (men and women) were recruited from households with children between 6 and 60 months of age. For this age group that is more at risk of malnutrition and their mothers, household dietary intake, feeding practices, and particularly ASF intake, is critical for growth and development. Purposive non-probability sampling was utilized to recruit the in-depth interviews (IDIs) and FGD participants to include consenting men and women of reproductive age in a couple-based family (with spouses living together with their children) in the informal settlements of Dagoretti North and South.

The study utilized qualitative methods namely in-depth interviews (IDIs), focus group discussions and key informant interviews (KIIs) complemented by unstructured observations, to inform the study aim to explore the drivers of ASFs choice and consumption. A total of 19 FGDs which included participatory exercises comprised of 7 groups of men and 12 groups of women each with 12 participants. For engaging in the participatory exercises, the FGD groups were further split into smaller groups of 6 people to enable more engagement. A total of 60 IDIs comprised of 40 women and 20 men and the $19 \mathrm{KIIS}$ were conducted with 19 informants sampled purposively from the health and nutrition sector state and nonstate actors. The IDI, KII and FGDs were conducted separately for men and women to moderate power dynamics that may limit participants of either gender from fully engaging in an honest discussion and representing their opinion in the presence of the other gender. The FGDs were complemented by unstructured observations, to explore the drivers of ASFs choice and consumption.

Interview guides were used to guide the FGDs and IDIs to gather detailed information on the issues until the information was saturated. The IDIs and FGD guides were designed based on the Agriculture for Nutrition and Health (ANH) Food Environment framework (FEWG) [12] as reflected in the structure and style of the focus groups and interviews, which were framed with open-ended questions relating to dietary practices and household decision-making around food including choice and consumption of ASFs. Targeted probing questions based on respondents' comments allowed for a participant-directed discussion. The FGDs combined different techniques like free listing, scenarios and pile sorting to collect more nuanced information and take the conversation beyond normative.

All the interviews and discussions were conducted by trained research assistants as interviewer, moderator and notetaker respectively. Swahili was the language of interviews and discussion as the 
participants represented multiplicity of ethnic backgrounds with varying vernacular languages but well conversant in Swahili. The research assistants took the study participants through the informed consent form and the information sheet provided to all participants before the start of the interviews and/ discussions. Questions and concerns from the participants were addressed before written consent was obtained. FGDs and IDIs were recorded using digital audio recorders with permission from the study participants in addition to the informed consent to capture any lost data. Recordings were later reviewed and compared to the fieldnotes captured by the note taker to ensure data quality. Data was transcribed alongside the fieldnotes and translated into English transcripts for coding and analysis given that the interviews had been conducted in Swahili.

Names of informants and places that were identifiers were replaced with pseudonyms on the transcripts for anonymity and confidentiality of the study participants. The study utilized gender and intersectionality approach to guide the analysis hinged on the inductive approach in grounded theory. The transcripts were reviewed for quality and a code tree developed following review of the transcripts to identify emerging codes. Coding was done on NVivo and themes were directly drawn from the data to inform the study questions.

\section{Results}

\section{Socio-demographics of participants:}

The mean age of the women was 32.7 years (range 18-73 years). Most of them were casual workers and only five were employed in the government or private sector. A majority were currently married. The mean age of the Men respondents was 34.3 years (range 17-59 years). Majority of the men were also casual workers with only seven employed in government or private sector. Majority of the respondents (98\%) were Christians. The study setting that is a heterogenous population with representation of diverse ethnicities from all over Kenya with the most represented in the study including the Agikuyu, Abaluhya, Ameru, Akamba, Kalenjin, Dholuo and Abagusii.

\section{Decision making on what ASF to purchase}

In terms of accessing ASFs there were different possibilities across the households interviewed and these were often defined by traditional, social and cultural definitions of roles and responsibilities of men and women across ethnicities and backgrounds represented in the informal settings.

In most instances, men would leave money for food and the women would plan a daily meal schedule to fit within the resources. In majority of the household's women bought food items required including ASFs:

In my house, let's say he can provide a specific amount of money then it is me who will budget using that cash. After being given that cash it is me who decides what to do with it and how long it will last me.'(Women's FGD 12) 
'For me it is my wife who decides while on my part I provide the money'. (Men's FGD06).

There were a few households where the men would buy the household food items and bring them home. In these, the men would bring on a daily or weekly basis the food items including ASFs. This was especially common where the women were just stay-at-home mothers with no source of income. Such women depend on their spouses to provide and make most of the decisions in the household, driven mostly by their preferences when it comes to food including ASFs: 'Most of the time they[women] do not buy what you tell them. Let us say I want to consume mutton (goat) so I leave the money to purchase that mutton (goat), I will not even find it prepared I will be told the child was unwell so the money was used to take the child to hospital. Instead what I will find on the table is omena. So for me, I would rather take the responsibility and bring the meat to the table and my wife cooks it.' (Men's FGD04).

'In my home, my husband doesn't like meat unless he decides by himself to bring the meat, even if we tell him we want meat, he will not buy unless he decides by himself.' (Women's IDI 19).

I am the one who buys beef or fish... because you may find that when I am paid I might come back home with three quarters of meat or some good fish, Just to surprise my family. Most of the times, the money I leave as I go to work is not enough to buy things like beef it is just enough to buy the usual food.' (Men's IDI 55)

\section{Women's contribution to ASF budget}

The study setting comprised short term income opportunities for men and women. The informal and short-term nature of work opportunities and the little pay was often not enough for men to cater for the family needs, including food budgets in a setting where the population is mostly dependent on market supply: 'It is him who provides but sometimes I also do... you know sometimes he doesn't have a job so I will look for casual jobs so I will then provide.'(women's IDI36). Women reported that therefore they would often need to also make their own contributions to supplement those family budgets. In this setting women reported to access small incomes as they doubled up as caregivers of the home and children: 'As a woman, you can buy food because maybe your husband doesn't have money and you have done some casual jobs or someone has given you something small, you will just buy because you can wait for your husband to come back, only to say he doesn't have money so you just have to buy.' (Women's FGD04)

Women alongside their husband's would find work opportunities to earn some incomes. These incomes were accessible through income generation activities like doing laundry or bead work, or running small businesses like selling vegetables or second-hand clothes and at times being in women self-help groups:

'Maybe you have washed cloths for someone and have gotten some two hundred shillings, you will just have to buy[food]. You won't wait to be told go and buy this, you just decide on your own.' (Women's FGD 01)

Especially the woman needs to plan for herself. You cannot depend on your husband. Your husband can be having another family somewhere and you are sitting waiting for money and there is none. The 
children are the ones who will suffer. So, the woman should plan for herself.' (Women FGD 12)

However, there were in some cases potential for conflict fueled by cultural narratives on bread winners in families. Participants noted that in some households there would be conflicts or discomfort of some sorts if the woman buys meat because he (the man) does not know the source of money:

if she buys meat, it can lead to conflicts. The question being where she got the money to buy meat. She should tell you where that luck has come from.' (Men's FGD 07)

'... if a woman buys ASFs like meat, and the husband does not know where the money came from, he cannot eat that meat. Even if you cook, he'd rather sleep hungry or you cook for him vegetables. He believes his money is what should buy meat in the home and then he will eat.'(Women's FGD 13)

Socio-culturally driven perceptions define men as the main providers for household budgets including food, in the study setting, but women contribution was necessary to supplement the men's income and meet the needs. While it was culturally not supported, men were increasingly acknowledging the contribution of women to household budgets including food in the constrained resource settings: 'The way the economy is right now the wife should also have a part to play in a contribution. If you contribute three hundred she should also contribute fifty shillings.'(Men's FGD 08)

Men were embracing the necessity to have women also earn incomes to supplement household budgets. 'The house is for both of you, the wife and the husband. There is no third person so you need to help each other. Marriage is about helping each other and not relying on one person.' (Men's FGD 07). Through the participation of women in household food budgets, consumption of ASFs in the urban informal settings was much more: 'We are eating more ASsF because we do not sit and wait. If I get a casual job and get two hundred shillings then I buy it, not that I am there waiting for my husband to bring.'(Women's FGD 10)

\section{Intra-household allocation and consumption of ASF}

The ASFs distribution and allocation practices were often fueled by cultural beliefs and traditions which were often similar across Kenya's numerous ethnicities. The allocation of and distribution of food including ASFs was defined by social-cultural norms and perceptions and continued to persist even in urban settings such as the study area. In this study because the chicken was considered a delicacy, participants referred to it to illustrate this dimension: 'Let me speak only on chicken. If we are children in a house, we are not supposed to eat "imondo" [Gizzard]. The gizzards are preserved for the head of the family while the children eat the legs and the "matumbo" [offals].' (Men's FGD08)

'We were brought up believing that the chicken gizzard was tasty and therefore it was for men and not women.' (Women's FGDO7)

'In our homes, the children should eat the head and the legs of the chicken and the rest is of the meat but the 'imondo' is meant for the man, the woman cannot eat it. In the absence of the husband, the gizzard is 
eaten by the eldest son.' (Men's FGD 02)

A recurrent theme was men being prioritized in ASF distribution in family meals. Women from the culturally diverse FGDs were of the view that men came first in terms of order of serving, size of portions and parts of ASF to be consumed: 'It is better you serve him a lot of food the first time and then later the child will serve for himself. For the sake of respect you must teach them especially the girls that in their homes the man is given more food, you need to teach them so in the future they will know how to serve their husbands, because you must serve the older person.'(Women's FGD 13)

'I will start with my husband because he is the head and then the children. The best way is for me to serve the children, for example if you have cooked chicken or meat, the child will run for what is meant for the man. That's why it is good for the mother to serve everyone.' (Women's FGD 13)

'But I will serve him first, and allow the children to serve for themselves what has remained.' (Women's IDI 10)

Women often placed themselves last after ensuring everyone else is well taken care of. It was perceived that men as the household heads needed larger portions of food especially ASFs to compensate for their hard work and also as a sign of respect: '/ serve my husband first and he is also the one to get the largest quantity because he is the head of the household. If it is fermented milk he will drink one cup and me and the child will share one cup.' (Women's IDI 45)

It was also evident that women and children also seemed to have similar consumption habits which may disadvantage their consumption of ASF: 'I serve my husband first, unless these ones[the children] are crying and he hasn't come back then I will serve them and I am the last one. He might come with visitors then you serve them and the food is finished before I eat. Then I have to go back to the shop to look for something to eat.' (Women's IDI 35)

'The father gets more because he does a lot of work then the kids. You know we as mothers sometimes sacrifice so that the kids get something.' (Women's IDI 44)

Men were also of similar perspectives when talking about ASFs distribution and allocation in the households. They also emphasized the role of women in distribution and allocation of food: 'My wife usually takes care of all that. Cooking as well as serving. Because she knows which parts and what quantity each family member should have and what will get each satisfied. We eat however she serves.' (Men's IDI 48)

\section{Weaning and ASF prescriptions and proscriptions}

Nutritional beliefs attributed to the recommended ASFs were discussed by respondents. These types of ASF were believed to boosts a child's immunity, increase a child's intelligence, strengthen bones and make a child grow strong. The commonly mentioned ASFs were milk, liver, fish and 'omena': 
'Obviously, a child needs milk whether it is from the cow or from the mother herself it will help him. So, milk is important for a child. The child becomes strong. You know there is a difference between a child who has breastfed and one who has not. Even if you give them milk from the cow, the one from the mother is still important.' (Women's FGD 05)

'Since I have a baby who is one-year-old, I use omena soup to give her so as to strengthen her immune system. In the process I also see that we eat a lot of omena as a family not only because of this nutrition issue but also because it is cheap and available. So, I have put omena high in my list of priority.' (Men's FGD 03)

Infants and children were considered highly sensitive to stomach upset based on the belief that they cannot digest foods as effectively as adults. Prevention of upset stomach was the most common reason for excluding certain foods especially ASFs from infant's and children's diets. The reported ASFs of this kind were undiluted milk and eggs: 'Children are not like us, and you know eggs are proteins. That is the first thing we should note and then also if you are going to give them eggs give them boiled eggs, not the one with oil, I also hear that you do not give them the yolk because the egg has too much proteins and if you give them the yolk every day it might give the child a problem.' (Women's FGD 07)

If it is milk only, it will be too heavy for the child and the child will have constipation... It will be difficult for the child to go to the toilet. The water that is used to dilute the milk will help in digestion.' (Women's IDI03)

The perceptions with egg consumption were associated with delayed development milestones for children:

'Something else about eggs, there is also a belief that if you have a child who has not started speaking/talking and you give them eggs from time to time, they will have challenges of speech development, they will be late to speak or talk. So, giving eggs to children who are yet to talk is somehow discouraged. '(Men's FGD 06)

'I started giving him eggs when he was two years. In our culture they say when you give a child eggs when they are still young, they will delay to talk.' (Women's IDI06)

'So, these eggs, especially the indigenous ones they say it is 'strong' and so they don't give them to young children.' (Men's IDI18)

These community prescriptions and proscriptions for food were corroborated by the nutrition professionals in the study area: 'We have a perception about eggs because mothers think that if they give babies eggs, they might delay to talk. We are trying to break that misconception by counselling them. There have been issues in this community so we are trying to tell them that it is a misconception.' (Nutritionist KII04)

\section{ASF preparation}


Notably in preparation of ASFs, the culturally assigned role of women to prepare meals was also articulated. Both men and women agreed that food including ASFs preparation was a women's domain: 'It is my wife who cooks and serves the food.'(Men's IDI 49)

Men only helped with preparation of food including ASFs when the women were unwell or away from home:

'He can't cook. Unless I am very sick, bedridden, then he will cook. But the next day if he comes and find you sitting down, he will just leave you there and go. You will just have to cook even if you are still unwell. Because if you don't cook, it is the children who will suffer, so you just have to.'(Women's IDI 35)

'I hardly go to the kitchen to see whatever is being cooked or how it is prepared. Not unless she is unwell and my children are unable to prepare any food, that is when I step in.'(Men's FGD02)

Food preparation is seen solely as the duty of women. Notably though when it came to ASFs men were at times involved in determining how it is prepared: 'And you have come with meat, she will ask you how you want us to cook this meat. You can tell her, boil for me a portion of it because I want to drink soup. The other portion you will know how to cook it'., (Men FGD 06)

Women articulated the power position and influence of men in the ASF preparation. In the household's the preference of men on which ASF and how it is prepared was highly considered:

'That will depend on how long you have lived with him because the longer you live with him, the better you come to know what he likes and how it is cooked, whether it is fried or boiled you will already have known. And once he comes with the meat you will know whether to fry or boil it.' (Women's FGD 13)

'He might come with the meat and say today let's not cook soup there you will know he wants it fried or he will suggest that the meat he has brought has a lot of oil, then you will know you will not add oil to the meat. You will only put your tomatoes and onions.'(Women's FGD 12)

It emerged that in some households the men would offer to even prepare the ASFs to suit their preference because they did not trust their wives to cook it to their preference:

'There are foods that I don't know how to cook and he might want to eat them, so he cooks. Like omena he will cook for himself among other things.' (Women's IDI 44)

'If you buy the meat and take it to her, you will not eat that meat. Because I am the one who knows how to cook meat. She will cook it but you cannot eat it since she cannot cook it the way I want. So, you have to teach her.' (Men's FGD 04)

'I don't know how to cook chicken so it is my husband who cooks.' (Women's IDI 45)

This though was an aspect for further investigation as it was emerging and not fully exhausted in this study. 


\section{Coping strategies when there is no money}

Men as the providers would provide money for household food needs and they would then leave some amount of money on a daily basis for household food needs given their wage-based incomes.

Sometimes when they[men] haven't left money, men are now utilizing mobile money transfer services to fulfill this: "I can say this, buying is not a problem it depends on the environment, where you are... You can be far from your wife but you can send her money through mpesa for her to buy food....' (Men's FGD02)

With mobile money transfers, it was now possible to meet family food needs by sending money so that it is available at the needed time: 'He just sends you money and tells you what to buy.' (Women's IDI 17)

'You can come home with meat you arrive at 10.00 pm when the children are asleep; will they benefit? You see, they will just hear that in our house there was meat you see (Men's FGD 19)

While mobile money transfers were helpful, there were instances where households did not have enough money and wished to consume ASFs. At such times, a good relationship, for both the men and women with a retailer would come in handy to enable access to ASFs like milk and meat on credit: '/ will buy from one retailer because I know if I don't have cash I can purchase my goods on credit. If he is my customer he will give me items on credit but if I start buying here and there he will just know that I go to his place only for credit, so you just have to have one retailer.'(Women's FGD09)

I buy meat from one butcher. Like if I do not have money and I want to get meat on credit, I go there because at the time of need, the retailer understands that you are their customer and can therefore sell to you on credit.'(Men's IDI 13).

'... we are accustomed to this one because he brings quality meat, you may go and buy somewhere else, and you will doubt the quality (Men's IDI, 19).

Interestingly, both men and women seemed to cultivated trust relationships with retailers to secure not only the quality of products but also provide a basis for credit. To also cope when there was limited cash income for household food and nutrition needs, households in urban informal settings often accessed cheaper options for ASF either through buying smaller portions. Women would for instance buy meat / beef for as little as KES 50 and supplement their meals: 'These days we have devices that measure the kilos and give the prices. So, we are able to buy according to how much one has. For example, what the old lady has said that you can afford fifty bob meat and you cook with Sukuma[kales] and share with your family.' (Women's FGD 11)

Households in lower-income urban informal settings would also cope in instances of limited incomes by opting for cheaper varieties of ASF, like in the case of chicken, men would buy small cut pieces of chicken such as, legs, necks, gizzards and this would in their case satisfy the craving at that time to want to consume chicken. When these were bought it didn't matter what part of a chicken it was, it counted just as chicken all together. For men the need to be able to provide food including ASF was fulfilled regardless 
as children would be happy to eat 'chicken' even if just as pieces, and the men would derive their satisfaction from being able to provide: 'Children also like katakata, these are parts of a chicken and in addition they are cheap. For instance, this katakata if you go and buy chicken feet worth 50 shillings, if you have a family and you cook it well, children will be satisfied and feel like they have eaten chicken.' (Male FGD 07)

'So that the children don't say that they don't eat chicken. They say, "Dad has brought us chicken." ... at that time, you have bought about 30 chicken legs. Every child gets about 5 legs. With that the children do not feel like they have been left out when maybe others have.'(Men's FGD 09)

Women too were happy to access these cheaper varieties of ASF to meet a need for consuming a particular ASF: 'Katakata [chicken cut pieces] is good because the person who has not kept chicken and not able to buy will be able to buy, can buy for 30 or 20 shillings and add to the kales and they will feel like they have eaten chicken.'(Women's FGD 05)

The cheaper ASF varieties satisfied the nutrition and preference for ASF for families in informal settlements often challenged by limited incomes. Men were often looking at the cost of ASF including milk to make a purchase and here the raw milk was more accessed because it was a cheaper option to enable the family to be able to enjoy milk:

'Because the one from the shop is packaged so it is expensive but this one from the vendors, they sell 20 shillings for one cup and in the shop it is 50 shillings- the packaged one so depending on my ability, I find the one from the vendors to be good.' (Men's IDI 5)

'Raw milk is cheaper because I can get for twenty shillings a cup while the packet of milk that costs KEs 50 shillings.'(Men's IDI 55)

While the cheaper ASF varieties were options for meeting ASF needs and easily accessed in informal markets, they were often unvalidated for quality and safety. The emic perspectives emerging around ASF food safety in informal settings with limited incomes are covered in another paper to be published by the same authors

\section{Discussion}

Within the study setting in the coupled households', the decision on what is consumed by who in households involves the co-evolution of practices within the fabric of social power structures reflecting intra-household power dynamics. These power positions in households are along the axes of age and gender as social expectations performed through food including ASF practices.

As illustrated in this study and in existing literature, household decision making on purchase and consumption of ASFs was mainly fueled by socioeconomic status (SES) but also informed by the intersecting gender and age considerations that drive intrahousehold allocation and consumption $[4,5,7]$. Women's contribution to household budget and coping mechanisms to enable ASFs access in the 
absence of money were articulated as the key factors influencing ASFs dietary intake for households in lower-income urban informal settings of Nairobi. The availability of mobile money transfers (Mpesa) had made it possible for men to better support their household food needs as emergent in the study. Notably the leveraging on mutual trust between retailer and consumers to enable access to ASFs on credit matches well with the quantitative component of this study to be shortly published by the authors.

Women in urban informal settings increasingly play a central role in food and nutrition security for their households through short term income generation wage-based and self-organization activities. This enforces the idea that women's decision-making autonomy is an important aspect of women empowerment, as it relates to women's dietary diversity and subsequently, better nutritional status. As evidenced in this study, if a woman has bargaining power based on accessing incomes to support their household food needs, they will not jeopardize food security. Notably, whilst men were the socio-culturally designated bread winners expected to provide for the family budgets, women are increasingly contributing to supplement household food needs. This has increased women's bargaining power and decision making in food decisions including access, choice and consumption of ASFs as illustrated in the findings. Women reported more consumption of ASFs in households where they contribute to food budgets. There is evidence that women's participation in household decision-making and ability to purchase food including ASFs (an aspect of empowerment) is corelated with availability of diverse diet in the household. Various elements of women empowerment and disempowerment for that matter have been linked to lower or higher nutritional risks respectively [1, 4, 5]. A study in Nepal concludes that higher SES is associated significantly with more frequent consumption of most food groups, including ASFs, inseason fruits and vegetables [13]. Also, a positive association between increases in women's empowerment and improved nutrition outcomes has been documented and any actions leading to women's disempowerment can result in adverse nutritional impacts for women and children limiting their access to ASFs that provide important micronutrients for nutrition and wellbeing. Studies in Kenya, Ghana, Bangladesh and Vietnam observed a positive association between maternal education and maternal dietary diversity $[1,4,5,14]$.

However, from this study man were seen to have strong preferences for ASFs and influence the purchase, preparation and allocation in households. In most discussions, men talked of their role as providers of money to meet the family's needs while the women's role as deciding what to buy and prepare. Most men did not want to get involved in the kitchen work as food preparation is a task traditionally assigned to women. Men also seemed to have a general feeling that women are responsible for buying vegetables, eggs, milk, cheaper meat varieties like the chicken pieces, [katakata] and small fish [omena] often costing from as low as KES 20, while the men are the ones to come home with meat from the butchery that is often of higher value. This could suggest that men had complete control of when to consume specific ASFs particularly meat. This is supported further when discussants talk about buying meat as they come from work and others talking about sending money to their wives asking them to buy meat and others talking about how they leave money for purchasing meat before leaving for work. The finding is similar to a study done in Uganda and Zambia which revealed that women had more control and decision-making power when it came to decisions on what to eat in relation to vegetables whereas the men controlled 
decisions about consumption of animal source foods such as meat, fish and eggs [15].This could suggest that the challenges of malnutrition can be reduced if men would also be targeted for improved nutrition programs and interventions. It is important for nutrition programs to include men to ensure the availability of diverse diets in the households.

Further, decision-making to purchase ASFs in the lower-income urban informal study setting had a larger household component than previously considered in the more high-income settings [16]. In lower- income urban informal settings families had to consider household size and composition in terms of gender and age often influenced by socio-cultural norms to determine if, when and what ASF is to be bought and consumed. Also the preference of especially the men as head of household and the prescription of ASFs for young children also influenced the choice and consumption. This takes place in a context where the economic status already is a key factor that influences consumption. The most crucial decisional point was affordability in terms of costs, followed by food preferences of husband and children. On intrahousehold allocation and consumption of ASFs, differences in the distribution and consumption of food especially based on age and gender are seen in this study as also captured in other contexts as defined by social-cultural norms. Age-based differences in consumption of ASFs do exist, but the form differs based on socio-cultural backgrounds represented in the study setting. In food allocation men were considered more than women and children.

Cultural norms, taboos and beliefs lie within the contextual factors included as one of the basic causes of malnutrition $[17,18]$. Local beliefs and cultural practices on ASFs choice and consumption as illustrated in this study prioritize men and limit particularly ASFs consumption by women and children, the household members who could benefit the most from ASF intake [8]. In this current study children are given smaller food portions including meat with preference to feed them on the soups from the meat stews, but more milk portions with the notion that they cannot eat meat chunks, and benefit more from the soups and milk. A study done in Uganda showed that providing men with larger portions of meat was seen as an encouragement for men to continue buying meat for the household. Women were also afraid that if they did not follow the custom, their husbands might leave them and go to women who gave them more meat [15]. Looking further into the prescriptions and proscriptions of ASF especially for women and children would inform the design of culture and gender sensitive programs and interventions targeted at tackling malnutrition in such settings.

Ultimately as detailed in this study, gender and sociocultural factors are seen to intersect with attitudes and practices to influence ASFs dietary intake for households in lower-income urban informal settings. It is also undeniable that economic status including the contribution of women to household budgets at the household level is tied to access to ASFs. This essentially affects how much women and children access and benefit from ASFs-based diets to address malnutrition.

\section{Conclusions}


This exploratory study found gender and decision-making intersect with household economic status and sociocultural practices to drive ASFs (and food more broadly) access for women and children. Gendered relations mediate processes of decision-making on the access, choice and consumption of ASFs and how these dynamics may affect the nutritional status of different members within the households. Women's contribution and coping mechanisms in the absence of money are highlighted alongside sociocultural factors to explore household access to ASFs by men, women and children. Through these results and discussions this paper contributes to locally relevant research on associations between gender and other factors and how these influence ASFs dietary intake for households in lower-income urban informal settings. Further, it has implications for nutrition-sensitive programs seeking to address the underlying causes of undernutrition in women and children in low-income resource limited settings.

\section{Recommendations}

Further research to include rural-urban settings is necessary to inform the association of gender and other factors and how these influence ASFs dietary intake for households on a broader more diverse scale.

Designing of nutrition programs including education modules need to incorporate gender and socialcultural intersecting factors to inform and ASF choice and consumption and address the underlying causes of malnutrition (undernutrition) in women and children in low-income resource-limited settings.

\section{Abbreviations}

ANH Agriculture for Nutrition and Health

ASFs $\quad$ Animal Source Foods

FGDs $\quad$ Focus Group Discussions

IDIs In-depth interviews

FAO Food and Agriculture Organization of the United Nations

FEWG Food Environment framework

SES Socio-economic status

IAGAS Institute of Anthropology, Gender and African Studies

LSHTM London School of Hygiene and Tropical Medicine

LCIRAH Leverhulme Centre for Integrative Research on Agriculture and Health

NRI Natural Resources Institute 

UoN
University of Nairobi
ILRI International Livestock Research Institute

\section{Declarations}

\section{Ethical Approval and Consent to participate}

The study received ethical clearance from the International Livestock Research Institute (ILRI) Institutional Research Ethics Committee (IREC) (reference number: ILRI-IREC2018-16/1). All study participants provided informed written consent.

\section{Consent for publication}

Not applicable

\section{Availability of supporting data}

The datasets used and/or analyzed during the current study are available from the corresponding author on reasonable request.

\section{Competing interests}

The authors declare that they have no competing interests.

\section{Funding}

This research was funded by the Drivers of Food Choice (DFC) Competitive Grants Programs, (Grant no: INV-008124), which is funded by the Foreign, Commonwealth and Development Office (FCDO) and the Bill \& Melinda Gates Foundation, and managed by the University of South Carolina, Arnold School of Public Health, USA; however, the views expressed do not necessarily reflect the UK Government's official policies. The funding body had no role in data collection, analysis, interpretation of data and writing the manuscript.

\section{Authors' contributions}

Paula Domínguez-Salas (PD-S), Suneetha Kadiyala (SK), Salome A. Bukachi (SAB) and Aurélia Lépine (AL) conceived the broader study. Aurélia Lépine, Salome A. Bukachi and Paula Domínguez-Salas oversaw the implementation of the study, Mariah Ngutu (MN) and Salome A. Bukachi conceptualized and designed the manuscript, Salome A. Bukachi, Mariah Ngutu and Ann W. Muthiru (AWM) conducted the data collection, entry and analysis, MN with support from Salome A. Bukachi and AWM wrote the first draft of the manuscript, Suneetha Kadiyala, Aurélia Lépine and Paula Domínguez-Salas critically reviewed and edited the manuscript, Mariah Ngutu, Mariah Ngutu Salome A. Bukachi and Ann W. Muthiru polished up the manuscript. All authors have read and approved the final version of the manuscript.

\section{Acknowledgement}


The authors want to thank all the participants whose voluntary participation and invaluable contribution in this study made it possible.

\section{Author's information}

${ }^{1}$ Institute of Anthropology, Gender and African Studies (IAGAS), University of Nairobi (UoN), IAS Museum Hill, NAIROBI, Kenya.

${ }^{2}$ University College London (UCL), Gower Street, London WC1E 6BT. United Kingdom

${ }^{3}$ London School of Hygiene and Tropical Medicine (LSHTM) \& Leverhulme Centre for Integrative Research on Agriculture and Health (LCIRAH),Keppel St, Bloomsbury, London WC1E 7HT, United Kingdom

${ }^{4}$ Natural Resources Institute (NRI) University of Greenwich, Medway Campus, Central Avenue, Chatham Maritime, Kent, ME4 4TB, UK

${ }^{5}$ International Livestock Research Institute (ILRI) , Naivasha Rd, Nairobi, Kenya

\section{References}

Maitra, C., (2018). A review of studies examining the link between food insecurity and malnutrition. Technical Paper. FAO, Rome. 70pp. Licence: CC BY-NC-SA 3.0 IGO. (Available at http://www.fao.org/3/CA1447EN/ca1447en.pdf).

(1996), Food, Agriculture and Food Security: Developments since the World Food Conference and Prospects, Technical Background Document No 1 for the World Food Summit, Rome.

Kenya National Bureau of Statistics, Ministry of Health, National AIDS Control Council, Kenya Medical Research Institute, National Council for Population and Development and ICF International (2015). Kenya Demographic and Health Survey 2014. Nairobi, Kenya and Rockville, MD: KNBS and The DHS Program/ICF International.

Muraya, K., Jones, C., Berkley, J., and Molyneux S. (2017). "If it's issues to do with nutrition...I can decide...": gendered decision-making in joining community-based child nutrition interventions within rural coastal Kenya. Health Policy and Plan, 32(5):31-39

Dominguez-Salas P, Alarcón, B. Häsler, I. R. Dohoo, K. Colverson, E. W. Kimani-Murage, S. Alonso, E. Ferguson, E. M. Fèvre, J. Rushton and, Delia,G. (2016). Nutritional characterisation of low-income households in deprived areas of Nairobi: socioeconomic, livestock and gender considerations and predictors of malnutrition from a cross-sectional survey. BMC Nutrition $2: 47$. https://doi.org/10.1186/s40795-016-0086-2 
Amugsi, D.A., Lartey, A., Kimani-Murage, E., and Mberu, B. (2016) Women's participation in household decision-making and higher dietary diversity: findings from nationally representative data from Ghana. Journal of Health Population and Nutrition 35:16. DOI 10.1186/s41043-016-0053-1

Grace, D., Dominguez-Salas, P., Alonso, S., Lannerstad, M., Muunda, E., Ngwili, N., Omar, A., Khan, M. and Otobo E. (2018). The influence of livestock-derived foods on nutrition during the first 1,000 days of life. ILRI Research Report 44. Nairobi, Kenya: International Livestock Research Institute (ILRI)

Harris-Fry, H., Saville, N., Shrestha, N., Costello, A. (2017). Determinants of intra-household food allocation between adults in South Asia - a systematic review. International Journal for Equity in Health 16:107

Nyangweso, P.M.; Odhiambo, M.O.; Odunga, P.; Korir, M. K.; Kipsa, M. J.;and Serem, A. K. (2007). Household food security in Vihiga district, Kenya: determinants of dietary and diversity. African Crop Science Society conference proceedings, El-Minia, Egypt 8:1383-1389.

Hetherington, J.,Wiethoelter, A., Negin,J., Mor,S.M.,(2017). Animal source foods and child nutrtional outcomes in seven rural village clustres in Sub-Saharan Africa.Agriculture \& Food Security 6:9. https:// doi.org/10.1186/s40066-016-0079-z

Luo,W., Zhai,F., Jin,S., Ge,K.(2001). Intrahousehold food distribution: a case study of eight provinces in China.Asia Pacific Journal of Clinical Nutrition. 10:19-28

Turner, C., Kadiyala, S., Aggarwal, A., Coates, J., Drewnowski, A.,Hawkes, C., Herforth, A., Kalamatianou, S., Walls, H. (2017). Concepts and methods for food environment research in low and middle income countries. Agriculture, Nutrition and Health Academy Food Environments Working Group (ANH-FEWG). Innovative Methods and Metrics for Agriculture and Nutrition Actions (IMMANA) programme. London, UK FAO. (2016) The State Of Food and Agriculture: Climate Change, Agriculture and Food Security: Rome, Italy

Ruel, M.,Quisumbing, A.,\& Balagamwala, M.(2017). Nutrition-sensitive agriculture: what have we learned and where do we go from here? IFPRI Discussion Paper 1681. Washington,D.C.: IFPRI

KIT, SNV, CDI, SDC, 2017. Intra-household dynamics and dietary diversity. Insights from Sustainable Nutrition for All in Uganda and Zambia. Technical Paper No. 3. SNV Netherlands Development Organisation, The Hague, The Netherlands.

Malapit, H., \& Quisumbing, A., (2016). Gendered pathways to better nutrition. Rural 21:15-17. https://www.rural21.com/uploads/media/rural2016_01-S15-17.pdf

Paudel, R., Pradhan, B., Wagle, R., Pahari, D., Onta, S. (2012). Risk Factors for Stunting Among Children: A Community Based Case Control Study in Nepal. Kathmandu University Medical Journal 10 (39):18-24. 
Galiè, A., Teufel, N., Girard,A.W., Baltenweck, I., Dominguez-Salas,P., Price,M., Jones, R., Lukuyu, B., Korir,L., IlanaG., Raskind, Kristie, S., Kathryn, M. Yount (2019). Women's empowerment, food security and nutrition of pastoral communities in Tanzania. Global Food Security 23:125-134 